\title{
Lost in Translation? \\ Challenges in Connecting Reading Science and Educational Practice
}

\author{
Mark S. Seidenberg \\ University of Wisconsin-Madison \\ Matt Cooper Borkenhagen \\ University of Wisconsin-Madison \\ Devin M. Kearns \\ University of Connecticut
}

\begin{abstract}
Mark S. Seidenberg. (D) https://orcid.org/0000-0001-8519-3259
Matt Cooper Borkenhagen. (D) https://orcid.org/0000-0002-8245-0130

Devin M. Kearns. (D) http://orcid.org/0000-0001-9703-0932
\end{abstract}

Preparation of this article was supported by the Vilas Trust, University of Wisconsin-Madison (MCB, MSS), Deinlein Language and Literacy Fund (MSS), and IES grant R305B150003 (MCB). DMK was supported by NICHD grant 5P20HD091013-03. The opinions expressed are those of the authors and do not represent views of the US Department of Education. Correspondence concerning this article should be addressed to Mark S. Seidenberg, seidenberg@wisc.edu.

This is the peer reviewed version of the following article:

Seidenberg, M. S., Borkenhagen, M. C., \& Kearns, D. M. (in press). Lost in translation? Challenges in connecting reading science and educational practice. Reading Research Quarterly. 


\begin{abstract}
Can the science of reading contribute to improving educational practices, allowing more children to become skilled readers? Much has been learned about the behavioral and brain bases of reading, how children learn to read, and factors that contribute to low literacy. The potential to use research findings to improve literacy outcomes is substantial but remains largely unrealized. The lack of improvement in literacy levels, especially among children who face other challenges such as poverty, has led to new pressure to incorporate the "science of reading" in curricula, instructional practices, and teacher education. In the interest of promoting these efforts, we discuss three issues that could undermine them: the need for additional translational research linking reading science to classroom activities; the oversimplified way the science is sometimes represented in the educational context; the fact that theories of reading have become more complex and less intuitive as the field has progressed. Addressing these concerns may allow reading science to be used more effectively and achieve greater acceptance among educators.
\end{abstract}

Keywords: reading science, translational research, reading instruction, statistical learning, quasiregularity 


\section{Lost in Translation? Challenges in Connecting Reading Science and Educational Practice}

Reading is a remarkably complex activity involving most of our mental and neural capacities. As such it has been the focus of a massive amount of research by scientists from numerous disciplines who study human behavior and its brain bases. This interdisciplinary body of research constitutes what is sometimes called the "science of reading" (for reviews see Castles, Rastle, \& Nation, 2018; Rayner, Foorman, Perfetti, Pesetsky, \& Seidenberg, 2001; Seidenberg, 2017; Snowling \& Hulme, 2005). Many scientists who conduct this research have long believed that it could be used to improve educational practices and literacy outcomes (Adams, 1990; Stanovich \& Stanovich, 2003; and previous references). That would be valuable, given persistently low literacy levels in the US and other countries, especially among groups for whom factors such as poverty create many additional obstacles (Snow, Burns, \& Griffin, 1998; Reardon, 2013). Previous efforts to connect this research and educational practice have failed for a variety of reasons (Seidenberg, 2017). The lack of improvement in literacy outcomes over a many-year period has led to new pressure to incorporate the "science of reading" in curricula, instructional practices, and teacher education (Gewertz, 2020; Hurford, 2020). The pursuit of legislative remedies for low reading achievement in nearly every state (Dyslegia, 2020; National Conference of State Legislatures, 2019) is indicative of frustration over the lack of progress in addressing well-founded concerns.

These actions have revived longstanding disagreements about the causes of low literacy and how to address them. The arguments are distressingly familiar from the "reading wars" (for varied accounts, see Kim, 2008; Lemann, 1997; WETA, 2003). According to Seidenberg (2017), disagreements about reading education are a manifestation of a disconnection between the cultures of science and education, dating from the creation of American schools of education in the early $20^{\text {th }}$ century. Research on cognitive, linguistic, social, and emotional development that is highly relevant to education has been only fitfully incorporated in programs for teachers, curriculum developers, administrators, and policy experts. Educators working with scientists of an earlier era developed approaches to reading instruction based on assumptions that were falsified by extensive research, but these findings have had little impact on what teachers are taught, and widely-used instructional materials continue to incorporate them (Seidenberg, 2019, discusses one example).

The fact that the same conflicts have persisted under different names (skills vs. literacy; phonics vs. whole language; phonics vs. balanced literacy) while literacy levels have been stagnant indicates that a different approach is needed. Concerns about reading instruction and teacher preparedness have been amplified via social media, advocacy groups, books (e.g., Goldstein, 2015; Seidenberg, 2017), and investigative journalism (Hanford, 2018), creating opportunity for change. Several states have initiated reforms centered on increasing teachers' familiarity with the "science of reading," mandating the use of instructional practices that are consistent with it. Such efforts are gaining momentum (Gewertz, 2020). 
Renewed interest in using reading research to improve practices is a welcome development. The potential benefits are substantial but remain largely untapped. The research base is extensive. Yet debates about connecting science and practice have hardly changed (compare articles in this issue with Stanovich \& Stanovich, 2003, or Kim, 2008). Education is an enormous enterprise with numerous stakeholders whose interests often conflict: government, academia, business, voters, taxpayers, teachers, advocacy groups, families, children-and reading researchers. Change is exceedingly difficult to accomplish.

Many observers (e.g., Blaunstein \& Lyon, 2006; Steiner \& Rozen, 2004) have criticized the educational establishment, focusing on the schools of education that provide professional training for teachers and administrators, and are the home for experts in curriculum and instruction, policy, and other areas. The schools are not all alike; they contain numerous departments that represent different fields; and individuals' views certainly vary greatly. Reading science is conducted by some researchers in schools of education. Historically, however, they have deflected the influence of such science in teacher education, the development of curricula and practices, and in educational philosophy, rationalizing why it lacks relevance and placing greater emphasis on a canon of accepted findings from earlier eras (Seidenberg, 2017). Scientific literacy - familiarity with core research findings; the ability to critically assess the quality of a research study, the validity of the conclusions, their relation to other findings-is still not strongly emphasized in professional training, leaving practitioners susceptible to discredited or unsupported claims (e.g., the persistence of "neuromyths"; Dekker, Lee, HowardJones, \& Jolles, 2012). Findings are cherry-picked from the vast literature to support personal beliefs and sell products.

Many educators reject the premise that their policies and practices are a major factor in poor reading achievement. Diane Ravitch's (2011) argument that poor educational outcomes are due to external factors - principally poverty and government interference in her view-was enormously influential. It successfully deflected attention away from improving quality of education for the children for whom it matters most; it ignored the ways that educational practices magnify the impact of income inequality; and it wrongly implied that low literacy is limited to people in poverty (Seidenberg, 2017, pp. 223-230). Still, relative to poverty and government policy, using research to improve outcomes seems almost inconsequential. Similarly, the invention of "balanced literacy" successfully diffused the reading wars at their peak in the early 2000s without addressing the underlying issues. Declarations about the relevance of phonics by organizations historically opposed to it (e.g., International Literacy Association, 2019) could have a similar effect unless coupled to actions that change policies and practices.

The pedagogical status quo is also sustained via a closed loop that includes educational authorities (academia), government (local, state, and federal officials who control budgets and policies), and educational publishing and technology corporations (producers of instructional 
materials). Many such authorities work closely with state departments of education and create products for the vast education market.

We do not wish to minimize the importance of these conditions, which create real obstacles that demand continued attention with the goal of achieving significant reforms. However, acknowledging other conditions affecting educational outcomes does not obviate the need to examine educational quality, which also has a strong impact especially for children subject to other risk factors (Aikens \& Barbarin, 2008). If the science of reading can improve children's learning and literacy, we need to use it, other factors notwithstanding.

Our goal is to examine ways to make better use of science to improve outcomes, at a time when interest in the possibility is growing. We have concerns about uses of the "science of reading" that could undermine well-intentioned attempts to bring research to bear on pedagogy. The main products of this science are findings - systematic data about phenomena - and, more important, theories that are our best explanations for such findings. In reading, we have numerous theories because it is a complex behavior, the product of multiple skills and capacities; because reading is not a uniform activity but rather varies depending on purpose, skill, type of material, and context; and because it can be viewed from multiple intersecting perspectives (e.g., biological, behavioral, social, developmental, cross-cultural).

A theory of how children gain reading skills should (minimally) address what, how, when, and for whom. The what component is a characterization of the types of knowledge and mental operations ("processes") relevant to tasks such as reading aloud and comprehending stories. The how part is a characterization of how the what is learned. The goal is a mechanistic account of how a learner gets from point A (e.g., child cannot yet read) to point B (child achieves escape velocity: basic skills that can develop further without much additional instruction). The when part refers to the fact that reading, like other acquired forms of expertise (e.g., gymnastics, mathematics), develops over an extended period of time. The nature of the skill demands that elements be introduced over time. So does the nature of the child: capacities to learn change with development; what a child is able to learn also depends on the current state of their knowledge, which changes as they progress. For whom refers to individual differences among children that also determine answers to the other questions. For example, a child who is a native speaker of a different language or dialect than the one used in school has different needs than a child who can already read because they were taught at home.

Every teacher acts on the basis of a tacit theory of what, how, when and for whom, based on what they have been taught, learned from peers, and discovered from experience. The curricula they use also instantiate assumptions in each of these areas. Incorporating reading science is valuable because it adds a vast amount to what is known about how reading works and children learn, beyond what can be established by other means.

We have three concerns about current efforts to use this science to improve reading outcomes. First, there is a need for additional translational research to establish closer connections between theory and practice. We know more about the science of reading than about 
the science of teaching based on the science of reading. Second, we are concerned about how reading science is characterized in educational contexts: It can be oversimplified in ways that slow progress by seeming to sanction practices that are only loosely connected to it. Finally, the "science of reading" is a moving target because it continues to progress. Theories have grown increasingly complex and counterintuitive, creating additional translational challenges.

We raise these concerns because the extensive body of research about reading may be used more effectively, and achieve greater acceptance, if they are addressed.

\section{Lost in Translation?}

Reading science does not come with educational prescriptions attached. Science is one kind of thing (empirical findings, explanatory theories). Educational practice is another (activities that promote learning in real-world settings). Connecting the two is the function of translational research. Given what is known about how reading works and children learn, what should be taught, when, and how? Which approaches are effective? For which children from which backgrounds and socioeconomic circumstances? Much has been learned from studies that used scientific theories and methods to investigate components of effective reading instruction (e.g., Vellutino, Tunmer, Jaccard, \& Chen, 2007), devise effective interventions (e.g., McGinty, Breit-Smith, Fan, Justice, \& Kaderavek, 2011; Morris et al., 2012), and identify factors that predict reading outcomes (e.g., Kim, Petscher, Schatschneider, \& Foorman, 2010). Our concern is that although reading science is highly relevant to learning in the classroom setting, it does not yet speak to what to teach, when, how and for whom at a level that is useful for a teacher.

To illustrate, consider research on the effectiveness of instruction that focuses on increasing children's knowledge of lexical phonology. Beginning readers who are progressing more rapidly exhibit better knowledge of the phonological properties of words, as measured by "phonological awareness" tasks such as deciding if two words rhyme, indicating the number of syllables in words, and deciding if two words end with the same sound or contain the same vowel (Castles et al., 2018). We know why: reading depends on speech. Children do not re-learn language when they learn to read; they learn to relate the printed code to existing knowledge of spoken language. Writing systems are codes for representing spoken language (Seidenberg, 2017, pp. 31-55). The structure of spoken words in English--the fact they consist of sequences of phonemes, syllables, and morphemes, that are associated with meaning--is reflected in their alphabetic representations. Learning about the written code is easier for children who know more about characteristics of spoken words that it represents. Individual differences in knowledge of such properties of spoken language at the start of formal instruction have an enormous impact on children's progress (Hulme, Nash, Gooch, Lervåg, \& Snowling, 2015).

The translational question, however, is what to teach. For example, is it effective to focus instruction on building "phonological awareness"? Interventions of this sort have yielded very mixed results (Bus \& Van Ijzendoorn, 1999). Sometimes improvement on the specific tasks 
there were the focus of instruction does not carry over to other tasks, like reading comprehension (Blachman, 1997).

The picture changes if we consider the impact of such instruction in conjunction with other activities. Many studies indicate that "phonological awareness" instruction is more effective when linked to instruction about print and meaning (e.g., Ball \& Blachman, 1991; Bowyer-Crane et al., 2008; Byrne \& Fielding-Barnsley, 1989; Cunningham, 1990; Gillon, 2000; Hatcher, Hulme, \& Ellis, 1994; Schuele \& Boudreau, 2008; Stuebing Barth, Cirino, Francis, \& Fletcher, 2008). Theories of reading can easily explain these results. The goal is gaining proficiency in reading (i.e., comprehending words and texts). Reading comprehension is facilitated by using print to access existing knowledge of spoken language. The development of phonological representations of words relevant to reading depends on experience with both spoken language and print. Thus, phonologically-focused instruction is more effective when linked to knowledge of print in the service of reading for meaning.

That is good science, but what are the implications for instruction? Keeping in mind that the research in question concerns school-aged children, not pre-schoolers, they are something like: Avoid teaching phonological awareness in isolation; emphasize connections between spelling, sound, and meaning; do so in the context of actual reading, the development of which is the instructional goal. Guidelines of this sort are useful. They might influence how teachers construe and pursue their instructional goals. But, they do not speak to how to accomplish these goals. A teacher is more likely to seek that information from Pinterest and teacherspayteachers.com. A lot of reading research has this character. The science is excellent. It is how we've learned so much about how reading works. Practitioners should know about it. Yet there is a need to go the final translational mile to impact practice.

In short, one reason the science doesn't get into the classroom is because it does not provide sufficient guidance about what to do there. It is not only that cognitive science is not a part of teacher education. If it were clear to teachers how such science could improve their effectiveness and their students' progress, they would clamor for it. Some already do.

The imbalance between basic and translational research creates other problems. Consider phonics, for example. "Phonics" is not an important concept in theories of reading. Behavioral and brain evidence show that for skilled readers orthography and phonology become deeply integrated (Seidenberg, 2017). For struggling readers orthography and phonology are more weakly connected (Shankweiler et al., 2008). The obvious implication is that, among other activities, early reading instruction should include ones that facilitate acquiring knowledge of the correspondences between print and sound-"phonics."

"Phonics" is a translational issue. There is research relevant to developing effective phonics instruction, demonstrating for example the advantage of direct instruction over indirect methods (e.g., Foorman, Francis, Fletcher, Schatschneider, \& Mehta, 1998; Stuebing et al., 2008). However, the research literature does not provide detailed guidance about which spellingsound patterns to teach, how many to teach, whether patterns should be taught in isolation (e.g., 
all the pronunciations of the vowel $o$ ) or in disambiguating contexts (e.g., words such as cot, cold, cost, doll, off), or other issues that have to be adjudicated for instruction to proceed. The market is filled with phonics curricula that fill the translational gap but vary greatly in assumptions about what to teach, when, and how, and thus are unlikely to be equally effective. Programs are motivated by science - children need to learn these mappings, which requires instruction, ergo phonics - but research does not validate specific solutions. Yet that is what educators ask us: Which program does reading science say we should use?

In the absence of sufficient translational research, almost every reading curriculum can claim an equally loose connection to the "science of reading." The risk of course is that such programs will prove ineffective, not because the basic science was wrong but because the translation was poor. It has happened before. The unmet challenges involved in teaching phonics effectively, in the service of literacy, while maintaining student motivation and interest, led influential educators (e.g., Clay, 2001; Goodman, 1989; Krashen, 2002; Smith, 1999) to conclude that beginning readers would be better off without it - a profound mistake. The educational challenges have no bearing on the validity of the science; being hard to teach doesn't change how reading works or what children need to learn. Worse, the alternative approach they developed - utilizing "strategies" for guessing words from the context and other cues while discouraging the use of phonology by minimizing phonics instruction - make it harder to learn to recognize words quickly and accurately, a basic ingredient of reading skill (Seidenberg, 2017).

It might be thought that the science-to-practice translation would be achieved via the educational publishing industry that produces curricula and other materials for teachers. Popular curricula (e.g., McGraw-Hill's Wonders, August et al., 2014; Houghton Mifflin Harcourt's Journeys, Baumann et al., 2014; Fountas \& Pinnell, 2016; Calkins \& TCRWP Colleagues, 2019) are produced by teams of experts in education and science. Determining how science can be incorporated in such materials is presumably one of their tasks.

Commercial curricula do not accomplish this because they are compromised by the need to appeal to a broad market and to local authorities caught up in debates about best practices. The texts instantiate the "balanced literacy" idea that there isn't a single way to teach reading, and that teachers should be free to use elements from different approaches. Rather than offering a best-practices curriculum based on an effective translation of research to practice, teachers are left to construct their own. Their choices are likely to depend on their beliefs about reading and abilities to teach different kinds of material, not evidence-based recommendations about what to teach, how, when, and for whom.

\section{The "Science of Reading" in the Educational Context}

We have been placing the "science of reading" in quotes because the science that is the focus of legislation, in-service teacher training, and other educational reform is a simplified version of reading research. In these contexts, the "science of reading" concerns a relatively small number of key ideas and findings: the alphabetic principle (Liberman et al., 1989); the 
simple view of reading (Gough \& Tunmer, 1986); the 4-part processor (Moats \& Tolman, 2009); stages in development (Ehri, 2005); the 5 components of reading from the NRP report (NICHD, 2000), and a few others. Simplification is necessary to make research more accessible to teachers and other parties. It is a reasonable place to start, especially since the ideas are important yet still not universally known or accepted. But, reading science is an active, ongoing endeavor, not a canon of findings. Overreliance on simplified accounts of science risks reifying it into precepts that do not incorporate much of what the science has to offer.

To illustrate we turn to the National Reading Panel report. As everyone knows, the report was "an evidence-based assessment of the scientific research literature on reading and its implications for reading instruction." The panel identified five components for which instruction had been shown to be effective: phonemic awareness, phonics, fluency, vocabulary, and comprehension. The report has been discussed ad nauseum. It was valuable, serving several functions, including drawing attention to the existence of a body of science relevant to development and instruction. The reviews of evidence concerning phonemic awareness and phonics were historically significant given how negatively they were viewed in the whole language approach. The report was also widely critiqued (see Allington, 2002; Shanahan, 2004).

For our purposes, the main point is that the report was not a sufficient basis for designing an effective reading curriculum--but that is how it is frequently taken, today. The report mentioned but did not evaluate methods of instruction in each area. The panel did not evaluate existing curricula or describe the structure of an ideal curriculum based on their findings. That was not their charge. The report identified several targets for instruction supported by empirical research, but left open numerous questions about what to teach, when, how and for whom, as the authors acknowledged.

Why are these observations relevant some 20 years after the report was published? Because in the context of the "science of reading" and education, it is often taken as having established the scientific basis for early instruction. The five components have been codified as "the 5 pillars of instruction" that reading curricula should incorporate (Cassidy, Valadez, \& Garrett, 2010; Kim, 2008; McCardle \& Chhabra, 2005). It does not detract from the historical importance of the report to note that it is not suitable for this purpose. Leaving aside the report's limited scope, the five components are not the same kinds of things. Phonemic awareness is a type of knowledge. Phonics is a type of instruction about correspondences between spelling and sound. Fluency is a characteristic of skilled reading. Vocabulary is a primary component of language, and comprehension - well, that is the goal. Whereas phonemic awareness is a very specific type of knowledge, vocabulary and comprehension are broad categories subsuming numerous types of information and mental operations, including ones that are not specific to reading (e.g., knowledge of what happens in a restaurant; making inferences about people's beliefs and intentions). 
There is a further problem if these components of reading are treated independently, as in the NRP report (they were investigated by subgroups that wrote separate reports) and in curricula based on them. This is where the 5 pillars approach seriously departs from reading research. The science addresses types of information and processes involved in reading and how they develop. What is missing from the list of components is a developmental account of how they are learned, information that is crucial for instruction. Researchers have studied these issues extensively. In fact, the components are highly interdependent. Phonemic awareness - the ability to treat words as consisting of discrete sound segments - is the outcome of a developmental process that begins with learning a spoken language and is finished by exposure to print (Bertelson \& De Gelder, 1989). This process is affected by vocabulary size: Young children begin discovering the internal structure of words via the overlap between them, which depends on the range of words they know (Metsala \& Walley, 1998). Phonics--as it refers to learning spelling-sound correspondences--depends on phonemic awareness, but also vocabulary, which allows a learner to determine whether the way they pronounce a letter string matches a known word (Share, 1995). Vocabulary size and quality (Perfetti \& Hart, 2002) affect comprehension, but comprehension is also a source of vocabulary learning (Landauer \& Dumais, 1997). If these parts come together, the learner gains fluency in identifying and understanding words and texts, and if they are fluent they can read more and learn more from what they read, about orthography, phonology, morphology, vocabulary, grammar, the connections among these types of knowledge, the ways language is used to communicate and the things we communicate about. In short, the components interact (Rumelhart, 1977). Skilled reading is possible because of the dependencies between these types of knowledge. In acquisition, learning about one affects what is learned about others. Instruction based on these aspects of reading science would have a different character than practices based on separate components.

Our concern is not about the aged NRP report but about the way it is being used. It is not a good overview of the "science of reading" (too much is omitted) but is taken as such. It is not a sufficient basis for developing a curriculum, but is taken as such. In extreme cases we have observed, first grade reading instruction consists of blocks of time spent on each of the components, in the order they were presented in the report. The focus on the components leaves little time for reading and talking about books.

We have used the NRP report as our example, but the same questions can be raised about the use of other classic research. It is not that the ideas (the simple view of reading, the alphabetic principle, et al.) are wrong or unimportant; they are essential and need to be widely assimilated. Rather, they are incomplete, especially with regard to learning; they do not address individual differences adequately; they do not include important ideas and findings that came later, many of which they stimulated. Together with insufficient translational research, overreliance on canonical studies leaves the door open to varied practices that reading science does not sanction. 


\section{The Science of Statistical Learning in Quasiregular Domains}

We have discussed the need to bring reading science into closer contact with how learning occurs in educational settings. We observed that understanding what needs to be learned and how it is learned is a prerequisite for identifying effective practices, and that the science of reading is an active endeavor, not a canon of findings. Our final concern centers on the challenges involved in making use of research that has become highly technical and theories that may be counterintuitive.

As sciences advance, the phenomena that are studied become increasingly remote from everyday experience. Instruments like telescopes and microscopes led to the discovery of phenomena (galaxies, molecules) that would not otherwise be known to exist. Advances in methods for analyzing data reveal patterns that would not otherwise be detected. Despite reading's status as something we personally experience, such developments have occurred in reading science. Reading is mainly an internal event. The explanations for how we read refer to unobservable mental and neural operations. We study behaviors such as children's performance in matching words to pictures, reading sentences aloud with correct pronunciations and intonation, and answering questions about texts to draw inferences about these underlying events. However, the evidence now also includes data collected using specialized instruments (e.g., eyetracking, electroencephalography, neuroimaging), analyzed using advanced statistical and computational models that reveal "latent" factors, "hidden" knowledge, and neural activity. These tools have taken our understanding of reading beyond the realm of intuition and direct observation. The question is whether discoveries based on such methods can inform instructional practices.

We can again illustrate using phonics. Skilled readers use their knowledge of the correspondences between print and sound to generate the phonological codes for words in silent reading. What is this knowledge and how is it acquired? Given the properties of written English, logic suggests that two types of information must be involved: rules to produce patterns such as save-pave-gave, which are used in sounding out unfamiliar words (or, in research studies, pseudowords such as mave), and "exception" or "sight" words whose pronunciations violate the rules (e.g., have, said, bear) and must be memorized. For generations, dating back at least as far as the use of "phonic" methods in the early 19th century (Emans, 1968), this was the only account of how we manage to read words aloud. It is the core idea underlying the dual-route theory of reading (Coltheart, Davelaar, Jonasson, \& Besner, 1977; Coltheart, Rastle, Perry, Langdon, \& Ziegler, 2001). The instructional implications of the theory are straightforward: teach children the rules (or enough to allow them to "break the code"; Gough \& Hillinger, 1980), and help them memorize the exceptions.

Although rules-plus-sight words remains the basis of phonics instruction, the approach is inadequate in several respects. What are the rules for pronouncing written English? No one knows. There are many ad hoc lists of rules varying in number and coverage, and there is little evidence that readers employ specific rules such as those proposed by Coltheart et al. (2001) or 
Vousden, Ellefson, Solity, and Chater (2011). Beyond simple cases such as the pronunciation of vowels in CVC syllables, it is not clear what the rules are or even which words are rule-governed (Kearns, in press). Is spook an exception because of book and look, or rule-governed because of spoon and spool (Seidenberg, 2017, pp. 137-138)? Worse, it is unclear how children master the rules given that only a subset of them can be explicitly taught. Given these uncertainties, what should a teacher teach? The answer will depend on which phonics curriculum is being used or which instructional materials are downloaded from the internet.

Relating this theory to instruction raises a deeper question: What does a child need to "know" in order to read aloud? The word "know" is ambiguous, of course. It can't be that children need to "know" the rules of English pronunciation in the sense of being able to state them explicitly because no one can. Moreover, the conscious application of rules is slow and effortful, the opposite of fluent. Perhaps readers use rules without being consciously aware of them. But how does a person learn a rule without awareness? There are several algorithms for deriving rules from language data (e.g., Albright \& Hayes, 2003) but they are not realistic accounts of human rule induction. In phonics instruction, a subset of the rules is explicitly taught. How does explicit instruction turn into implicit knowledge and how does instruction in a subset of rules enable learning ones that are not taught? ${ }^{1}$

Given all of these concerns, one might ask: What if it is difficult to state the rules and how they are learned and decide on the sight words because the system isn't rule-governed? What if 200 years of phonics instruction has been based on a false dichotomy?

The issue was moot until an alternative theory was developed by Seidenberg and McClelland (1989). Their work incorporated ideas about artificial neural networks, the type of computational learning system that in later, more advanced forms underlies the powerful form of artificial intelligence called Deep Learning. The framework, implemented in a series of computational models, is described in detail elsewhere (e.g., Seidenberg, 2005; Plaut, 2005). Here we can only briefly consider the what and how questions from before. The what question is about the knowledge and processes that underlie reading aloud. A neural network model learns to perform this task, taking a spelling pattern as input and producing its pronunciation as output (Figure 1). The model represents knowledge of the correspondences between spelling and sound as a set of statistical dependencies (e.g., -ave is usually pronounced as in save but differently in have). The network learns these dependencies based on "experience" (i.e., presentations of words and their pronunciations) using a statistical learning procedure based on how such learning occurs in the brain. The models are not taught a pre-specified set of rules or mappings; they discover them through learning to perform the task.

\footnotetext{
${ }^{1}$ The same ambiguity arises about "awareness," as in phonological, phonemic, or morphological "awareness". The term "awareness" is unfortunate. Teachers need to be aware of what phonemes and morphemes are, in the sense of being able to describe and identify them accurately, which can then inform their instruction. Readers do not need to "know" these things, however; they merely have to use them, rapidly and unconsciously. People managed to learn to read for a couple of thousand years before linguists developed the concept of "phoneme".
} 


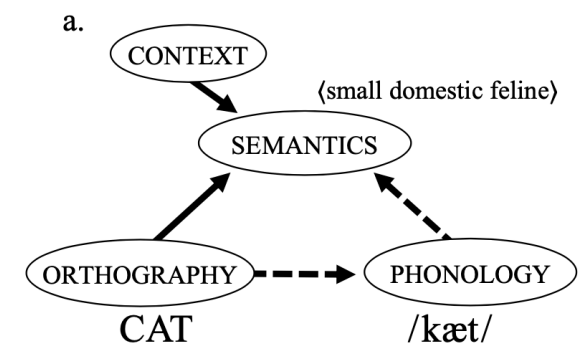

Panel (a) displays a schematic of the "triangle" framework (Seidenberg \& McClelland, 1989), showing the main components in a neural network model for reading words. Ovals represent layers of neuron-like processing units. Arrows represent connections between units. Implemented models include layers and connections not pictured here.

A model is given the spellings of words and learns to compute their meanings and/or sounds using feedback on many "training" trials. The ORTHOGRAPHY $\rightarrow$ PHONOLOGY pathway picks up on statistical patterns that support accurate performance. The trained model produces the correct pronunciations of both "rule-governed" (e.g., words like gave and paid), and "sight words" (e.g., have and said), and generalizes to novel strings such as mave and nust.

In learning to compute word meanings, the model initially relies on the ORTHOGRAPHY $\rightarrow$ PHONOLOGY $\rightarrow$ SEMANTICS pathway, but with additional experience, the ORTHOGRAPHY $\rightarrow$ SEMANTICS pathway also contributes, resulting in an efficient division of labor (Harm \& Seidenberg, 2004).

Models trained only on the ORTHOGRAPHY $\rightarrow$ SEMANTICS pathway take far longer to learn. The computed semantic pattern is integrated with the linguistic context in which a word occurs, which is crucial to resolving ambiguities and text comprehension.

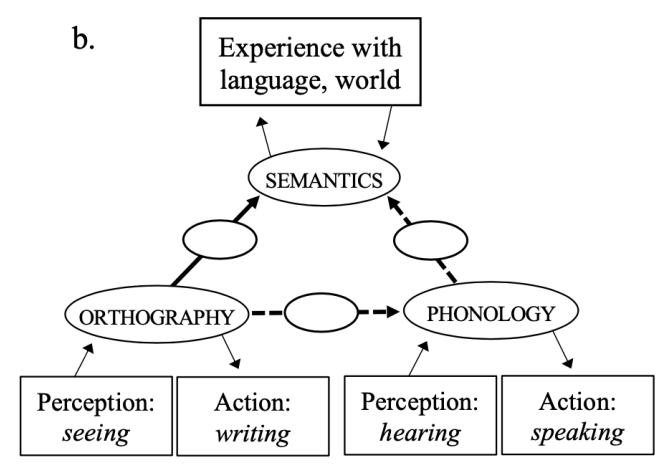

Panel (b) emphasizes the idea that orthography, phonology, and semantics are learned from perception and action. The phonological codes for words are shaped by their use in both hearing and producing spoken words. Orthography derives from seeing spelling patterns and producing them when we write. Semantics develops from perceiving the world (e.g., a tiger) but also using knowledge to act (e.g., deciding whether to approach a tiger).

Such models also include one or more layers of "hidden" units (small ovals), which allow the network to encode the underlying or "latent" structure of the mappings between codes.

Details about other important properties of such models are provided in references cited in the text.

\section{ORTHOGRAPHY $=$ spelling}

PHONOLOGY $=$ pronunciation $/$ sound

SEMANTICS $=$ meaning

CONTEXT $=$ sentence, text, situation

Figure 1. The Triangle Framework and Its Bases in Perception and Action

In this approach, words fall on a continuum of spelling-sound consistency, ranging from the most predictable, rule-like patterns to ones like colonel and diarrhea, which are pretty terrible. There isn't a distinction between "rule-governed" forms and "exceptions" because they share structure: exceptions like have, said, and glove overlap with other words such as had, send, and globe, respectively. In a neural network, what is learned about a word carries over to other, overlapping words. Knowledge of have affects performance on "rule-governed" words such as save and gave and generalization to novel forms like mave, evidence that they are learned, represented and processed within a common system. Knowledge that is rule-like but also admits patterns that deviate in varying degrees is termed quasiregular (Seidenberg \& McClelland, 1989). Quasiregularity is characteristic of language at many levels including syllables, morphology, words, and grammar (Bybee \& McClelland, 2005; Seidenberg \& Plaut, 2014).

Models developed within this framework account for many empirical phenomena related to spelling-sound correspondences, including facts about learning, the development of fluency, and characteristics of performance at different skill levels. Such models have also been applied to related phenomena, such as the computation of word meanings from print or speech, and guided research on the brain systems underlying reading (Compton et al., 2019; Graves et al., 2014; Ueno, Saito, Rogers, \& Ralph, 2011). 
This theory is not as intuitive as rules and exceptions. It is hard to explain and hard for researchers to analyze how such systems work. Exploring this approach requires considerable background knowledge. The models are also incomplete in many respects. Yet if they are a more accurate account of fundamental characteristics of reading, they should be relevant to instruction, bringing us to the how question.

Humans engage in at least two types of learning, explicit and implicit, also known as declarative and procedural (Ellis, 2005). The explicit system is associated with conscious awareness and intention, and procedures that can be described using language, such as the rules for chess. It is slow and effortful (cf. Kahneman, 2011's System 2 thinking, a related notion). The implicit system operates without conscious awareness, occurs automatically rather than by intent, and involves unlabeled statistical patterns (cf. Kahneman's System 1 thinking). The two systems work together, but their relative prominence depends on what is to be learned. Consider for example the contrast between how children learn the grammar of a first, spoken language and how older individuals learn the grammar of a second language. A first language is learned via observation and experience using language in communication. Children are not explicitly taught the rules of grammar; they pick up the structure of the language via statistical learning. They have little awareness of the patterns themselves, but learn to use them appropriately. We do eventually gain awareness of some patterns by studying them, but that is to refine the language we have already learned (e.g., to conform to academic expectations).

Learning a second language in school is different. Rules of grammar are usually explicitly taught. Learning depends heavily on already knowing a language (being able to read a textbook, translating from one language to the other) and requires intention and considerable effort. With extended study successful second language learners eventually begin encoding language statistics through usage.

The first and second language examples illustrate that both types of learning are involved in both cases, but the balance between them shifts: implicit statistical learning more prominent in L1, explicit rule learning and instruction in L2. The characteristics of first and second language learning differ as do the capacities of learners at different ages (Seidenberg \& Zevin, 2006).

The question then is: What kind of task is learning to read words? The models developed by Seidenberg and colleagues suggest that it mainly involves implicit learning of the statistical structure of mappings between form (orthography, phonology) and meaning. This learning occurs in the background as children engage in silent reading or reading aloud, or participate in other activities that provide opportunities to update this knowledge. The networks that support reading and language are updated every time we use them.

We also know, however, that some explicit instruction is necessary. Unlike very young children learning to talk, children don't begin to read until we teach them about reading, modeling it for them. Many aspects of written language are arbitrary, such as letter names and associated sounds. Children also must learn that print represents some aspects of spoken words (e.g., phonemic structure) but not many others that affect comprehension (voice quality, syllabic 
stress, accent, etc.). Some studies suggest that explicit instruction about a relatively small number of spelling-sound patterns can facilitate learning other, partially overlapping patterns (Steacy, Elleman, Lovett, \& Compton, 2016). Explicit instruction can be seen as enabling statistical learning, and timely, targeted instruction can further accelerate it (see Compton, Miller, Elleman, \& Steacy, 2014, for a related view). We do not yet know the optimal balance between the two systems for different learners, but learning phonics is more like learning a first language than learning a second one.

This framework isn't fully specified; much research remains to be conducted on the balance between the two learning systems, and how to translate those findings into effective practices. It does provide a useful perspective on the long-running debate about phonics, which arises from different assumptions about the types of learning involved. At one extreme, the child could be assumed to learn the correspondences on their own, an extreme implicit learning stance. This isn't correct because it ignores the role of explicit instruction in jump-starting the statistical learning component and accelerating it along the way to expertise.

At the other extreme, phonics programs often assume that these correspondences need to be exhaustively taught, like the rules of an exceedingly complex version of chess, in which the movements of the pieces are probabilistic and contingent on the surrounding pieces. Readers do not pronounce words by explicitly applying rules; doing so would be a conscious, slow effortful process (the opposite of "fluent"). Teaching phonics by teaching rules and memorizing exceptions leaves out the statistical patterns that permeate the system and drive the fast, implicit learning process.

We argue that neither extreme is correct. The goal is not "balanced literacy" but balanced learning: providing experiences that engage the implicit and explicit learning mechanisms to facilitate acquiring the statistical structure in quasiregular domains such as spelling-sound correspondences. This balance isn't well understood, but could be the focus of translational research. We have argued that instruction needs to cover what is necessary for children to learn, not merely what is familiar or easy. The same can be said of using the science of reading to inform instruction: We can't merely focus on what is familiar or easier to digest.

\section{Conclusion}

We began by noting that the potential for using reading research ("the science of reading") to improve literacy outcomes is substantial but largely untapped, and welcomed the renewed interest in making this connection. We identified three challenges to connecting science and practice (and there are others; see Table 1). These challenges are serious but can also be addressed. Doing so is likely to increase the utility of the science in the classroom and its acceptance as a source of insight about instruction, benefiting teachers and students. 
Table 1

Future Steps in Relating the Science of Reading to Educational Practice

1. Pursue cross-disciplinary collaborations. Summarizing findings and expecting others to pursue the implications has not been an effective strategy in reading science. Many types of scientific research require teams of individuals with complementary types of expertise. Translating reading science into verifiably effective educational practices does as well. Such teams are more likely to succeed at employing basic insights about reading and learning in ways that can be utilized by educators in the classroom.

2. Work towards a new science of teaching. Any theory of learning, including the one we've outlined here, should provide the following necessary information in the formation of a science of teaching. The result of such research should be the how of learning via teaching, accomplished by specifying what needs to be learned (the relevant sources of knowledge), when learning of a particular kind needs to occur, and for whom.

3. Avoid a narrow focus on phonics. Discussions about connecting the science of reading to education are often limited to phonics. The considerable research on this issue is only one part of a much larger body of research that addresses the many other elements of skilled reading and its development, including the many factors that affect children's progress. The science does speak to the importance of integrating print and sound early in development and to the role of instruction. However, it does so in the context of other skills and knowledge, their dependence on each other, and the time course of learning.

4. Invest in early learning. Many children are at risk for reading difficulties on the first day of school (Loeb \& Bassok, 2007), due in large part to individual differences in knowledge of spoken language and the world it is used to communicate about (Muter, Hulme, Snowling, \& Stevenson, 2004; Hoff, 2013). Increased translational research about what can be done in early learning contexts prior to the start of school will help fill in our knowledge of what we can do, when, and for which learners.

5. Develop a science of reading that applies to all readers. Most research on the science of reading is conducted with individuals from a narrow range of backgrounds. Conclusions based on this research cannot be assumed to generalize to understudied groups, including racial/ethnic minorities and individuals from low SES backgrounds. Deeper understanding of the impact of these individual difference factors is necessary to advance the science and its impact on education.

6. Examine existing systems of learning. Curricula and instruction can be assessed with respect to their coherence with known mechanisms of learning. Existing systems - from formal curricula to informal practices by individual teachers - should be examined and augmented in a way that moves them closer to what we know about how learners learn. 


\section{References}

Adams, M. J. (1990). Beginning to read: Learning and thinking about print. Cambridge: MIT.

Aikens, N. L., \& Barbarin, O. (2008). Socioeconomic differences in reading trajectories: The contribution of family, neighborhood, and school contexts. Journal of Educational Psychology, 100(2), 235-251. doi: 10.1037/0022-0663.100.2.235

Albright, A., \& Hayes, B. (2003). Rules vs. analogy in English past tenses: A computational/experimental study. Cognition, 90(2), 119-161. doi: 10.1016/s00100277(03)00146-X

Allington, R. (2002). Big brother and the national reading curriculum: How ideology trumped evidence. Portsmouth, NH: Heinemann.

August, D., Bear, D. R., Dole, J. A., Echevarria, J., Fisher, D., Francis, D., Gibson, V., Hasbrouck, J., Kilgo, M., McTighe, J., Paris, S. G., Shanahan, T., \& Tinajero, J. V. (2014). McGraw-Hill Reading Wonders: CCSS Reading Language Arts Program. New York, NY: McGraw-Hill Education.

Ball, E. W., \& Blachman, B. A. (1991). Does phoneme awareness training in kindergarten make a difference in early word recognition and developmental spelling? Reading Research Quarterly, 26(1), 49-66. doi: 10.1598/RRQ.26.1.3

Baumann, J. F., Chard, D. J., Cooks, J., Cooper, J. D. Gersten, R., Lipson, M., Morrow, L. M., Pikulski, J. J., Rivera, H. H., Rivera, M. Templeton, S., Valencia, S. W., Valentino, C., \& Vogt, M. (2014). Journeys: Common Core. Orlando, FL: Houghton Mifflin Harcourt Publishing Co.

Bertelson, P., \& De Gelder, B. (1989). Learning about reading from illiterates. In A. M. Galaburda (Ed.), Issues in the biology of language and cognition: From reading to neurons (pp. 1-23). Cambridge, MA: The MIT Press.

Blachman, B. (1997). Early intervention and phonological awareness: A cautionary tale. In B. Blachman (Ed.), Foundations of reading acquisition and dyslexia (pp. 409-430). Hillsdale, NJ: Lawrence Erlbaum Associates.

Blaunstein, P., \& Lyon, R. (2006). Why kids can't read: Challenging the status quo in education. Lanham, MD: Rowman \& Littlefield.

Bowyer-Crane, C., Snowling, M. J., Duff, F. J., Fieldsend, E., Carroll, J. M., Miles, J., ... \& Hulme, C. (2008). Improving early language and literacy skills: Differential effects of an oral language versus a phonology with reading intervention. Journal of Child Psychology and Psychiatry, 49(4), 422-432. doi: 10.1111/j.1469-7610.2007.01849.x

Bus, A. G., \& Van Ijzendoorn, M. H. (1999). Phonological awareness and early reading: A metaanalysis of experimental training studies. Journal of Educational Psychology, 91(3), 403414. doi: 10.1037/0022-0663.91.3.403 
Bybee, J., \& McClelland, J. L. (2005). Alternatives to the combinatorial paradigm of linguistic theory based on domain general principles of human cognition. The Linguistic Review, 22(2-4), 381-410. doi: 10.1515/tlir.2005.22.2-4.381

Byrne, B., \& Fielding-Barnsley, R. (1989). Phonemic awareness and letter knowledge in the child's acquisition of the alphabetic principle. Journal of Educational Psychology, 81(3), 313-321. doi: 10.1037/0022-0663.81.3.313

Calkins, L. (2019). No one gets to own the term "the science of reading”. Retrieved from https://drive.google.com/file/d/16Ewx2fZB4JEfP6aCAbTeN1L4F-34PnBX

Calkins, L., \& TCRWP Colleagues. (2019). Units of study in phonics. Portsmouth, NH: Heinemann.

Cassidy, J., Valadez, C. M., \& Garrett, S. D. (2010). Literacy trends and issues: A look at the five pillars and the cement that supports them. The Reading Teacher, 63(8), 644-655. doi: 10.1598/RT.63.8.3

Castles, A., Rastle, K., \& Nation, K. (2018). Ending the reading wars: Reading acquisition from novice to expert. Psychological Science in the Public Interest, 19(1), 5-51. doi: $10.1177 / 1529100618772271$

Clay, M. M. (2001). Change over time in children's literacy development. Portsmouth, NH: Heinemann.

Coltheart, M., Davelaar, E., Jonasson, J., \& Besner, D. (1977). Access to the internal lexicon. In S. Dornic (Ed.), Attention and performance VI (pp. 535-555). Hillsdale, NJ: Erlbaum.

Coltheart, M. (2005). Modeling reading: The dual-route approach. In M. J. Snowling \& C. Hulme (Eds.), The science of reading: A handbook (pp. 6-23). London: Blackwell.

Coltheart, M., Rastle, K., Perry, C., Langdon, R., \& Ziegler, J. (2001). DRC: A dual route cascaded model of visual word recognition and reading aloud. Psychological Review, 108(1), 204-256. doi: 10.1037/0033-295X.108.1.204

Compton, D. L., Miller, A. C., Elleman, A. M., \& Steacy, L. M. (2014). Have we forsaken reading theory in the name of "quick fix" interventions for children with reading disability? Scientific Studies of Reading, 18(1), 55-73. doi: 10.1080/10888438.2013.836200

Compton, D. L., Steacy, L. M., Petscher, Y., Rueckl, J. G., Landi, N., \& Pugh, K. R. (2019). Linking Behavioral and Computational Approaches to Better Understand Variant Vowel Pronunciations in Developing Readers. New directions for child and adolescent development, 2019(165), 55-71. doi: 10.1002/cad.20294

Cunningham, A. (1990). Explicit versus implicit instruction in phonemic awareness. Journal of Experimental Child Psychology, 50, 429-444. doi: 10.1016/0022-0965(90)90079-N 
Dekker, S., Lee, N. C., Howard-Jones, P., \& Jolles, J. (2012). Neuromyths in education: Prevalence and predictors of misconceptions among teachers. Frontiers in Psychology, 3, 429. doi: 10.3389/fpsyg.2012.00429

Dyslegia: A Legislative Information Site. (2020, May 22). State dyslexia laws [website]. Retrieved from https://www.dyslegia.com/state-dyslexia-laws/

Ehri., L.C. (2005). Development of sight word reading: Phases and findings. In M. J. Snowling \& C. Hulme (Eds.), The science of reading: A handbook (pp. 135-154). London: Blackwell.

Ellis, N. C. (2005). At the interface: Dynamic interactions of explicit and implicit language knowledge. Studies in Second Language Acquisition, 27(2), 305-352. doi: $10.1017 / \mathrm{S} 027226310505014 \mathrm{X}$

Emans, R. (1968). History of phonics. Elementary English, 45(5), 602-608.

Foorman, B. R., Francis, D. J., Fletcher, J. M., Schatschneider, C., \& Mehta, P. (1998). The role of instruction in learning to read: Preventing reading failure in at-risk children. Journal of Educational Psychology, 90(1), 37-55. doi: 10.1037/0022-0663.90.1.37

Fountas, I.C., \& Pinnell, G.S. (2016). The Fountas \& Pinnell Literacy Continuum: A tool for assessment, planning, and teaching. Portsmouth, NH: Heinemann.

Gewertz, C. (2020, February 20). States to schools: Teach reading the right way. Education Week. Retrieved from www.edweek.org/ew/articles/2020/02/20/states-to-schools-teachreading-the-right.html

Gillon, G. T. (2000). The efficacy of phonological awareness intervention for children with spoken language impairment. Language, Speech, and Hearing Services in Schools, 31(2), 126-141. doi: 10.1044/0161-1461.3102.126

Goldstein, D. (2015). The teacher wars: A history of America's most embattled profession. New York, NY: Anchor.

Goldstein, D. (2020, February 15). An old and contested solution to boost reading scores: Phonics. New York Times. Retrieved from www.nytimes.com/2020/02/15/us/readingphonics.html

Goodman, K. S. (1989). Whole-language research: Foundations and development. Elementary School Journal, 90(2), 207-221.

Gough, P. B., \& Hillinger, M. L. (1980). Learning to read: An unnatural act. Bulletin of the Orton Society, 30, 179-196. doi: 10.1007/BF02653717

Gough, P. B., \& Tunmer, W.E. (1986). Decoding, reading and reading disability. Remedial and Special Education, 7(1), 6-10. doi: 10.1177/074193258600700104 
Graves, W.W., Binder, J.R., Desai, R.H., Humphries, C., Stengel., B.C., \& Seidenberg, M.S. (2014). Anatomy is strategy: Skilled reading differences associated with structural connectivity differences in the reading network. Brain \& Language, 133, 1-13. doi: 10.1016/j.band1.2014.03.005

Hanford, E. (2018, September 10). Hard words: Why aren't kids being taught to read? APM Reports. Retrieved from www.apmreports.org/story/2018/09/10/hard-words-whyamerican-kids-arent-being-taught-to-read

Harm, M. W., \& Seidenberg, M. S. (2004). Computing the meanings of words in reading: Cooperative division of labor between visual and phonological processes. Psychological Review, 111(3), 662-720. doi: 10.1037/0033-295X.111.3.662

Hatcher, P. J., Hulme, C., \& Ellis, A. W. (1994). Ameliorating early reading failure by integrating the teaching of reading and phonological skills: The phonological linkage hypothesis. Child Development, 65(1), 41-57. doi: 10.1111/j.1467-8624.1994.tb00733.x

Hoff, E. (2013). Interpreting the early language trajectories of children from low-SES and language minority homes: Implications for closing achievement gaps. Developmental Psychology, 49(1), 4-14. doi: 10.1037/a0027238

Hulme, C., Nash, H. M., Gooch, D., Lervåg, A., \& Snowling, M. J. (2015). The foundations of literacy development in children at familial risk of dyslexia. Psychological Science, 26(12), 1877-1886. doi: 10.1177/0956797615603702

Hurford, D.P. (2020). The science of reading (a response to the New York Times). IDA Examiner, 9(1). Retrieved from https://dyslexiaida.org/the-science-of-reading-aresponse-to-the-new-york-times/

International Literacy Association. (2019). Meeting the challenges of early literacy phonics instruction [Literacy leadership brief]. Newark, DE: Author. Retrieved from https://www.literacyworldwide.org/docs/default-source/where-we-stand/ila-meetingchallenges-early-literacy-phonics-instruction.pdf

Kahneman, D. (2011). Thinking, fast and slow. New York: Macmillan.

Kearns, D. M. (in press). Does English have useful syllable division patterns? Reading Research Quarterly.

Kim, J. (2008). Research and the reading wars. In F. M. Hess (Ed.), When research matters: How scholarship influences education policy (pp. 89-111). Cambridge, MA: Harvard Education Press.

Kim, Y. S., Petscher, Y., Schatschneider, C., \& Foorman, B. (2010). Does growth rate in oral reading fluency matter in predicting reading comprehension achievement? Journal of Educational Psychology, 102(3), 652-667. doi: 10.1037/a0019643 
Krashen, S. (2002). Defending whole language: The limits of phonics instruction and the efficacy of whole language instruction. Reading Improvement, 39(1), 32-42.

Landauer, T. K., \& Dumais, S. T. (1997). A solution to Plato's problem: The latent semantic analysis theory of acquisition, induction, and representation of knowledge. Psychological Review, 104(2), 211-240. doi: 10.1037/0033-295X.104.2.211

Lemann, N. (1997, November). The reading wars. The Atlantic. Retrieved from https://www.theatlantic.com/magazine/archive/

Liberman, I. Y., Shankweiler, D., \& Liberman, A. M. (1989). The alphabetic principle and learning to read. Ann Arbor: University of Michigan Press. Retrieved from https://files.eric.ed.gov/fulltext/ED427291.pdf

Loeb, S., \& Bassok, D. (2007). Early childhood and the achievement gap. In H.F. Ladd \& E.B. Fiske (Eds.), Handbook of Research in Education Finance and Policy (pp. 517-534). Abingdon-on-Thames, England: Routledge Press.

McCardle, P., \& Chhabra, V. (2005). Motivation and commitment in the interest of science and our children. Phi Delta Kappan, 86(6), 448-451. doi: 10.1177/003172170508600608

McGinty, A. S., Breit-Smith, A., Fan, X., Justice, L. M., \& Kaderavek, J. N. (2011). Does intensity matter? Preschoolers' print knowledge development within a classroom-based intervention. Early Childhood Research Quarterly, 26(3), 255-267. doi: 10.1016/j.ecresq.2011.02.002

Metsala, J. L., \& Walley, A. C. (1998). Spoken vocabulary growth and the segmental restructuring of lexical representations: Precursors to phonemic awareness and early reading ability. In J. L. Metsala \& L. C. Ehri (Eds.), Word recognition in beginning literacy (pp. 89-120). New Jersey: Erlbaum.

Moats, L.C., \& Tolman, C. (2009). Language essentials for teachers of reading and spelling. Boston, MA: Sopris West Educational Services.

Morris, R. D., Lovett, M. W., Wolf, M., Sevcik, R. A., Steinbach, K. A., Frijters, J. C., \& Shapiro, M. B. (2012). Multiple-component remediation for developmental reading disabilities: IQ, socioeconomic status, and race as factors in remedial outcome. Journal of Learning Disabilities, 45(2), 99-127. doi: 10.1177/0022219409355472

Muter, V., Hulme, C., Snowling, M. J., \& Stevenson, J. (2004). Phonemes, rimes, vocabulary, and grammatical skills as foundations of early reading development: Evidence from a longitudinal study. Developmental Psychology, 40(5), 665-681. doi: 10.1037/00121649.40.5.665

National Conference of State Legislatures. (2019, April 16). Third-grade reading legislation [website]. https://www.ncsl.org/research/education/third-grade-reading-legislation.aspx 
National Institute of Child Health and Human Development. (2000). Report of the National Reading Panel. Teaching children to read: An evidence-based assessment of the scientific research literature on reading and its implications for reading instruction $(\mathrm{NIH}$ Publication No. 00-4769). Washington, DC: U.S. Government Printing Office.

Perfetti, C. A., \& Hart, L. (2002). The lexical quality hypothesis. In L. Verhoeven, C. Elbro, \& P. Reitsma (Eds.), Precursors of functional literacy (pp. 189-213). Amsterdam, Netherlands: John Benjamins Publishing Company.

Plaut, D.C. (2005). Connectionist approaches to reading. In M. J. Snowling \& C. Hulme (Eds.), The science of reading: A handbook (pp. 24-38). London: Blackwell.

Ravitch, D. (2011). The death and life of the great American school system: How testing and choice are undermining education. New York, NY: Basic Books.

Rayner, K., Foorman, B. R., Perfetti, C. A., Pesetsky, D., \& Seidenberg, M. S. (2001). How psychological science informs the teaching of reading. Psychological Science in the Public Interest, 2(2), 31-74. doi: 10.1111/1529-1006.00004

Reardon, S. F. (2013). The widening income achievement gap. Educational Leadership, 70(8), 10-16. Retrieved from http://www.ascd.org/publications/educationalleadership/may13/vol70/num08/The-Widening-Income-Achievement-Gap.aspx

Rumelhart, D.E. (1977). Toward an interactive model of reading. In S. Dornic (Ed.), Attention and performance VI (pp. 573-606). Hillsdale, NJ: Erlbaum.

Schuele, C. M., \& Boudreau, D. (2008). Phonological awareness intervention: Beyond the basics. Language, Speech, and Hearing Services in Schools, 39, 3-20. doi: 10.1044/01611461(2008/002)

Seidenberg, M. S. (2005). Connectionist models of word reading. Current Directions in Psychological Science, 14(5), 238-242. doi: 10.1111/j.0963-7214.2005.00372.x

Seidenberg, M.S. (2017). Language at the speed of sight: How we read, why so many can't, and what can be done about it. New York: Basic Books.

Seidenberg, M.S. (2019, December 9). This is why we don't have better readers: Response to Lucy Calkins [Web log post]. Retrieved from https://seidenbergreading.net/2019/12/06/lucy-calkins-on-the-attack/

Seidenberg, M. S., \& McClelland, J. L. (1989). A distributed, developmental model of word recognition and naming. Psychological Review, 96(4), 523-568. doi: 10.1037/0033295x.96.4.523

Seidenberg, M. S., \& Plaut, D. C. (2014). Quasiregularity and its discontents: The legacy of the past tense debate. Cognitive Science, 38(6), 1190-1228. doi: 10.1111/cogs.12147

Seidenberg, M. S., \& Zevin, J. D. (2006). Connectionist models in developmental cognitive 
neuroscience: Critical periods and the paradox of success. In Y. Munakata, \& M. H. Johnson (Eds.), Processes of change in brain and cognitive development: Attention and performance XXI (pp. 315-347). Oxford: Oxford University Press.

Shanahan, T. (2004). Critiques of the National Reading Panel Report: Their Implications for Research, Policy, and Practice. In P. McCardle \& V. Chhabra (Eds.), The voice of evidence in reading research (pp. 235-265). Baltimore, MD: Paul H Brookes Publishing Company.

Shankweiler, D., Mencl, W. E., Braze, D., Tabor, W., Pugh, K. R., \& Fulbright, R. K. (2008). Reading differences and brain: Cortical integration of speech and print in sentence processing varies with reader skill. Developmental Neuropsychology, 33(6), 745-775. doi: $10.1080 / 87565640802418688$

Share, D. L. (1995). Phonological recoding and self-teaching: Sine qua non of reading acquisition. Cognition, 55(2), 151-218. doi: 10.1016/0010-0277(94)00645-2

Smith, F. (1999). Why systematic phonics and phonemic awareness instruction constitute an educational hazard. Language Arts, 77(2), 150-155.

Snowling, M. J., \& Hulme, C. E. (2005). The science of reading: A handbook. London: Blackwell.

Snow, C. E., Burns, M. S., \& Griffin, P. (Eds.). (1998). Preventing reading difficulties in young children. Washington DC: National Academy Press. Retrieved from https://files.eric.ed.gov/fulltext/ED416465.pdf

Stanovich, P. J., \& Stanovich, K. E. (2003). Using research and reason in education: How teachers can use scientifically based research to make curricular \& instructional decisions. National Institute for Literacy.

Steacy, L. M., Elleman, A. M., Lovett, M. W., \& Compton, D. L. (2016). Exploring differential effects across two decoding treatments on item-level transfer in children with significant word reading difficulties: A new approach for testing intervention elements. Scientific Studies of Reading, 20(4), 283-295. doi: 10.1080/10888438.2016.1178267

Steiner, D. M., \& Rozen, S. D. (2004). Preparing tomorrow's teachers: An analysis of syllabi from a sample of America's schools of education. In F. M. Hess, A. J. Rotherham, \& K. Walsh (Eds.), A qualified teacher in every classroom? Appraising old answers and new ideas (pp. 119-148). Cambridge, MA: Harvard Education Press.

Stuebing, K. K., Barth, A. E., Cirino, P. T., Francis, D. J., \& Fletcher, J. M. (2008). A response to recent reanalyses of the National Reading Panel report: Effects of systematic phonics instruction are practically significant. Journal of Educational Psychology, 100(1), 123134. doi: 10.1037/0022-0663.100.1.123 
Ueno, T., Saito, S., Rogers, T. T., \& Ralph, M. A. L. (2011). Lichtheim 2: Synthesizing aphasia and the neural basis of language in a neurocomputational model of the dual dorsal-ventral language pathways. Neuron, 72(2), 385-396. doi: 10.1016/j.neuron.2011.09.013

Vellutino, F. R., Tunmer, W. E., Jaccard, J. J., \& Chen, R. (2007). Components of reading ability: Multivariate evidence for a convergent skills model of reading development. Scientific studies of reading, 11(1), 3-32. doi: 10.1080/10888430709336632

Vousden, J. I., Ellefson, M. R., Solity, J., \& Chater, N. (2011). Simplifying reading: Applying the simplicity principle to reading. Cognitive Science, 35(1), 34-78. doi: 10.1111/j.15516709.2010.01134.x

WETA (Producer). (2003). A tale of two schools: The documentary [DVD]. Available from https://www.pbs.org/weta/twoschools/documentary 